\title{
Prior Assessment of Variability in the Geotechnical Properties of Soils for Efficient Infrastructure Management
}

P.L. Dharamapriya ( $\sim$ prasannad@sci.pdn.ac.lk)

University of Peradeniya

H.A.H. Jayasena

University of Peradeniya

\section{Research Article}

Keywords: Geotechnical property, Dams, Wet and Dry zone, Statistical mean, Marshy, Residual, Alluvial, Coastal, and Compacted soils, Sri Lanka.

Posted Date: December 9th, 2021

DOl: https://doi.org/10.21203/rs.3.rs-1032504/v1

License: (c) (i) This work is licensed under a Creative Commons Attribution 4.0 International License.

Read Full License 


\section{Abstract}

Advance assessments of variations in geotechnical properties of soils are invaluable in making a crucial judgment of geotechnical engineering projects. It could drive to reduce the number of field and laboratory tests so that efficient management design and construction of infrastructure project outputs can be achieved. In this study, we aim at assessing the geotechnical properties of residual, alluvial, marshy, coastal, and compacted soils within the wet and the dry zones of Sri Lanka. Plastic limit (PL), liquid limit $(\mathrm{LL})$, shrinkage limit (SL), plasticity index (PI), liquidity index (LI), compression index (Cc), swell potential (SP), activity, natural moisture content (NMC) and SPT-N values were either extracted from reports or deduced from formulas and graphs. Wet zone marshy soils (My_W) show highest statistical means for PL ( 23\%), LL ( 40\%), PI ( 16 \%), SL ( 20\%), LI ( 1\%), Cc ( 0.200) and NMC ( 35\%), indicating poor engineering properties. Wet zone residual soils $\left(\mathrm{Re}_{-} \mathrm{W}\right)$ represent a wide range of direct correlations to the parent material. $\mathrm{CH}, \mathrm{OH}, \mathrm{CL}$ and $\mathrm{SM}$ soil groups for some My_W show high expansive, while, $\mathrm{CL}, \mathrm{Pt} / \mathrm{CL}$, OL, SC, SM in My_W, CL, and SC in Re_W and CL in Dry Zone Alluvial Soils (Al_D) display medium expansive. The higher SPT-N values were recorded in the upper $6.00 \mathrm{~m}$ and between $12.00-16.00 \mathrm{~m}$ for the shell of earth dams (SED_D) in the dry zone, in contrast to AI_D soils representing higher $\mathrm{N}$ values for $6.00-12.00 \mathrm{~m}$. Except for marshy soils, no vertical variation for plasticity was observed in others. Since high to medium swell potential in the unsaturated zone is encountered within the upper $1.50 \mathrm{~m}$, attention should pay to the My_W. LL and PI of My_W were strongly correlated $\left(\mathrm{R}^{2}=0.83\right)$ so that an equation PI\% $=-1.91+(0.46 * \mathrm{LL} \%)$ could be used to calculate PI. The results provide baseline geotechnical property variations for the five soils in Sri Lanka so that during planning, best-calculated assessment could be achieved which could minimize time and cost for crucial geotechnical investigations.

\section{Introduction}

From the dawn of civilization, humans always pay special attention to the dwelling structures where they could live safely and comfortably. History has shown us the longevity of building structures, aqueducts, bridges, and other infrastructure depending on sound foundations. However, foundations for such constructions cannot always be laid on solid rock, but often have to be located on unconsolidated soils. On top of that, the non-conservative nature of subsurface soils may pose additional problems in the construction. Therefore, geotechnical investigations of soils are becoming a primary tool in assessing the subsurface stability required for efficient infrastructure management facilities (e.g. Oke and Amadi 2008; Nwakwoala et al. 2009; Oyediran and Durojaiye 2011; Amadi et al. 2015). During pre-feasibility and feasibility studies of engineering projects, various "in-situ" and laboratory test methods have been employed as a prerequisite for appropriate design by the engineering geologist and the geotechnical engineers together. These investigations are usually time-consuming and costly; however, advance judgments on subsurface physical parameters before carrying out infrastructure projects with calculated assessment and some level of justification would be an asset to the design engineer (e.g. Madugalla et al. 2010; Jayasena et al. 2011). Several researchers have approached to provide a solution based on various empirical and case by case assessment mechanisms (e.g., Daniel and Benson 1990; Chenari et 
al. 2015). These studies particularly refer to the importance of prior knowledge of the behaviour of indices and strength properties concerning different soils. It could be usefully employed in performing basic engineering judgments where approximate cost estimations could be achieved in the pre-feasibility stage which could reduce unproductive field and laboratory tests in the feasibility stage. These subjects are constantly evolving and need new tools, which could improve the design and help better cope with the large uncertainties and variations in soil and rock properties. In this respect, geostatistics could also offer a window to analyze and create a spatial model for geotechnical properties of various soils (e.g. Seybold et al. 2008; Oyediran and Durojaiye 2011; Sideri et al. 2016), so that it can also be used as a primary tool for investigations of subsurface soils in new construction projects. Geostatistics can be defined as the tools for studying and predicting the spatial structure of georeferenced variables and the application has been extensively used in mining and soil science during the past few decades. However various inputs by many other related areas such as hydrogeology, geochemistry, meteorology, etc., paved the usefulness of the application of geostatistical methods (Krasilnikov et al. 2008).

Our objective was to acquire available geotechnical data from selected five different soil groups within the wet and the dry zones of Sri Lanka. We aimed at correlating significant geotechnical parameters and obtain characteristic relationships and specific patterns of variations within these soils, which could be used as a primary tool for geotechnical investigations. During this study, we mainly aimed at obtaining characteristic relationships and specific patterns on variations of index properties for the five different soils using SPT-N values of various soil groups in different soils. Subsequently, based on the above output attempt to correlate the strength properties of the soils. In addition, the variation of geotechnical properties of similar standard soil groups in different soils will also be assessed. Cost-effective testing methods based on spatial investigations and geostatistics will also expect to achieve.

\section{Geological And Climatic Setting Of Sri Lanka, And Study Areas}

\subsection{General geology of Sri Lanka}

The Precambrian basement of Sri Lanka is made up of four distinct crustal units identified based on the distribution of $\mathrm{Nd}$ model ages of a variety of lithologies, viz., the Highland Complex $(\mathrm{HC})(2.0-3.4 \mathrm{Ga})$, the Wanni Complex (WC) (1.1-1.8 Ga), and the Vijayan Complex (VC) (1.1-1.8 Ga) (Fig. 1) (Kroner et al. 1991; Milisenda et al. 1994; Cooray 1994). The Highland Complex is the largest unit and forms the backbone of the Precambrian rocks of Sri Lanka while metamorphosed under granulite facies conditions. WC and was metamorphosed under amphibolite - to granulite facies while the VC and KC were mostly under amphibolite - facies grade.

A few isolated occurrences of Jurassic sedimentary rocks occur within the northwest plains of the island at Tabbowa, Andigama, and Pallama (Pathirana 1980; Cooray 1984). They were formed within the faulted basins in the high-grade basement. In the extreme north and northwestern regions, adjacent to the $W C$ is a sequence of Miocene sedimentary rocks mainly associated with limestones and sandstones. These rocks are extending for about $100 \mathrm{~km}$ from Puttlum to Jaffna. Also, a sandstone sequence 
belonging to the Miocene age is located to the southern extremity of Sri Lanka and is known as the Minihagalkanda sandstone (Cooray 1984).

Extensive Quaternary sedimentary formations as different surficial deposits are also found within the island of Sri Lanka (e.g. Cooray 1984; Katupotha 1994). Those can be identified all along the coastal stretch and major river terraces (alluvial deposits). High-level terrace gravels, Rathnapura beds, coral beds, shell beds, lagoonal and estuary deposits, unconsolidated sands and beach rocks, red beds, and basal ferruginous gravels are the main quaternary formations (Cooray 1984; Katupotha 1994). Regarding engineering geologic and geotechnical investigations, this group of soils and formations are very important since many infrastructure and buildings are based on such deposits.

\subsection{Climate of Sri Lanka}

Sri Lanka is situated within 6 to 10 degrees latitudes to the North of the equator and falls within the tropical climate. Despite the small size of the island, it has been divided into three climatic zones namely dry, intermediate and wet according to the distribution of annual mean rainfall (Atlas of Sri Lanka 2007; Malmgren et al. 2007) (Fig. 2). The island is subjected to three types of rainfall, viz: monsoonal, conventional, and depression. The annual rainfall varies from $750 \mathrm{~mm}$ in very dry areas to over $5000 \mathrm{~mm}$ in highland areas, which governs the climatic conditions within the country (Mapa et al. 1999; Malmgren et al. 2007).

\subsection{Study Areas}

Six soil groups (wet zone's residual soil, alluvial soil, and marshy soil, and dry zone's alluvial soil, coastal soil, and soils in the shell of earth dams) were selected from six areas (Kandy and Kaduwela in the wet zone and, Madu, Batticaloa, Pottuvil and Polonnaruwa in the dry zone) in Sri Lanka to carry out the present study (Fig. 1a, b). Geotechnical properties of residual soils were studied from sampling sites around Kandy while Marshy soils were studied from Kaduwela. Coastal soils were studied from Batticaloa and Pottuvil while alluvial soils were studied from Kandy and Madhu. Compacted soils in the shell of earth dams were studied from the area around Polonnaruwa. A detailed description of topography, geology, soils and climate conditions of study areas have been given in supplementary document 1. Borehole locations of study areas have also been presented in supplementary Figures. 1, 2, 3,4 and 5 .

\section{Materials And Methods}

The project was preceded by three different phases as outlined below.

Phase I: Geotechnical reports with geotechnical and borehole log data on soil investigations were collected from two private geoengineering consulting firms (Geo-Engineering Consultant (Pvt) Ltd, Borella, and Soil Tech (Pvt) Ltd, Rajagiriya, Sri Lanka). Based on information collected from these geotechnical 
reports, and concurrent communications with engineering geologists and geotechnical engineers who worked in respective sites, the geotechnical data from residual, alluvial, marshy, coastal, and artificially compacted soils within the wet and the dry zones in Sri Lanka was selected circumspectly (Fig. 2). The standard data includes output from the sieve analysis (ASTM C136-06), Atterberg limits tests (ASTM D4318, including Plasticity index), and SPT (ASTM D1586). Except for coastal soils, data on natural moisture content (ASTM D2216) were also collected from other soils.

Phase II, Selected datasets were tabulated, and gross clay fraction was calculated from Skempton (1953), and Savage (2001) formula,

$P_{002}=6.25 P I \cdot P_{425} \cdot R^{-2.13}$

Where,

$\mathrm{P}_{002}=$ Gross clay fraction

$\mathrm{P}_{425}=$ Fraction of soil pass through $0.425 \mathrm{~mm}$ sieve

$\mathrm{Pl}=$ Plasticity index

$\mathrm{R}=\mathrm{LL} / \mathrm{PL}$ and may be termed the plasticity ratio

Subsequently, soils were classified according to the Unified Soil Classification System (USCS; ASTM D 2487-93). The compression indices (Cc) for residual soils were calculated using the formula, $\mathrm{Cc}=0.009$ (LL -10) (Skempton 1944) and for other selected soils from Cc $=0.007$ (LL-10) (Skempton 1944; Terzaghi and Peck 1967).

The activity of soils (a) was acquired by the formula $\mathrm{a}=\mathrm{Pl} /$ clay fraction $\%$ (Skempton, 1953) while the swell potential was obtained from Van Der Merwe's (1964) method. Also, the Liquidity index and textural classification of soils were calculated using ASTM D 4318 method and USDA classifications, respectively.

Based on SPT-N values (ASTM D 1586), Friction angle $\left(\varnothing^{0}\right)$, Relative density (\%), Competency (Meyehof 1956), Consistency, and Approximate Unconfined Compressive strength (Arvind and Dhananjaya 2003) were obtained.

The empirical formula derived from the calculation of PL of marshy soils was based on Regression Statistics and Pearson's product-moment correlation. Statistical analyses were done using QI Macros of Microsoft Excel and Origin-2008.

Phase III: Data obtained from phases I and II were analyzed by statistical, and graphical methods to obtain characteristic relationships and specific patterns of variation of geotechnical properties. 


\section{Results And Discussion}

In the following sections, the results were categorized under, textural classification (section 4.1), index properties (section 4.2), and an empirical formula derived for the plasticity index of marshy soils (section 4.4). SPT-N values and strength properties of soils were given in section 4.3 while an overview of the study was given in section 4.5 .

\subsection{Textural Classification}

According to USDA textural classification of soils (Figs. 2a, b, c, d, e, f), the wet zone residual soils (Re_W) and alluvial soils (AI_W) show similarities within the textural triangle (Figs. 2a, b). These soils have a similar fraction of sand, silt, and clay. Soils in both the Wet Zone marshy soils (My_W) and Dry Zone alluvial soils (AI_D) indicated a wide range of textural classes (Figs. 2c, d) implying poor sorting of soils in different layers. Whereas the Dry zone coastal soils (Co_D) and the shell of earth dams (SED_D) were significantly sorted.

However, the texture of soils alone does not tell all needed important information to know about soils, to predict their behaviour and suitability for different uses, because it is not considering the gravel fraction of soils.

\subsection{Index Properties}

Index properties could be used to describe the observable behaviour of the soils with their physical characteristics. Index properties such as the grain sizes distribution range, soil consistency (Atterberg limits), liquidity index, compression index, natural moisture content, the activity of soils, and swell potential of soils were studied.

\subsubsection{Soil groups and their grain sizes distribution ranges}

Soil gradation is an important aspect of geotechnical engineering because it is an indicator of other vital engineering properties such as compressibility, shear strength, and hydraulic conductivity. Lee (1961) noted that the colloidal content of clays provides the necessary plasticity or workability. Akinmusuru and Adebayo, (1981) indicated that the sand size particles contribute to the mechanical strength.

Figure 3 indicates partial size distribution ranges of studied soils. Although soil samples were classified with the same name, they contained different gravel, sand, silt, and clay fractions in different soils (see Figs. 3a, b, c, d, e, f). For example, sandy soil groups encountered in Re_W had a relatively small range of gravel fractions (Fig. 3a). However, the same soil group in SED_D (Fig. 3f) had a relatively high range of gravel fraction while particular soil groups that occurred in MY_W (Fig. 3c) are associated with either no or negligible amounts.

The highest gavel fractions associated with Al_W (Fig. 3b) fall within 7.00-7.45m, 11.00-11.45m, and $14.00-14.45 \mathrm{~m}$ depth range from the surface. These gravel beds might have been deposited after strong 
flood events. At present, remnants of large gravel deposits can be observed along with earlier flood plains of the Mahaveli river around Peradeniya. Marshy areas were associated with a relatively larger fraction of fine grains. However, considering the fine-grain soil groups of all other soils, it revealed that geomorphologically flat terrains with low elevations in the vicinity were responsible. Therefore, during the flood period, fine-grain particles may reach such marshy areas as suspension load and be deposited. Considering the same soil group, a sand fraction (e.g. in SC) is relatively highest in Co_D (Fig. 3e) while lowest in the shell of earth dams SED_D (Fig. 3f).

\subsubsection{Soil Consistency (Atterberg) Limits}

The consistency states of soils are extensively used both in the construction industry (buildings and roads) and in agricultural practices (Archer, 1972). The parameter is evaluated based on Shrinkage Limit (SL), Plastic Limit (PL), and Liquid Limits (LL). The consistency limits have also been repeatedly shown to be useful indicators of clay behaviour (Jefferson and Rogers, 1998; Mbagwa and Abeh, 1998; Keller and Dexter, 2012). In addition, consistency limits also provide information for interpreting a number of soil mechanical and physical properties such as the shear strength, compressibility, shrinkage, and swelling potentials, etc., (Archer 1975; Campbell 2001; McBride 2008; Seybold et al. 2008). Figure 4 indicates the variation of SL (Fig. 4a), PL (Fig. 4b), LL (Fig. 4c), and Plasticity Index (PI; Fig. 4d) of studied soils.SL variation of plastic soils does not make a significant difference except for Co_D which shows relatively low SL (Fig. 4a).

However, PL and LL exhibit significant differences among the studied soils (Figs. 4b and c). Arthur (1942) showed that the Atterberg limits have increased with decreasing particle size. Since My_W contains organic and inorganic clay-rich soil groups such as $\mathrm{OH}, \mathrm{OL}, \mathrm{Pt} / \mathrm{CL}, \mathrm{CH}$, and $\mathrm{CL}$, high $\mathrm{PL}$ and $\mathrm{LL}$ values can be observed. LL of soil is proportional to clay content (Skempton, 1944). Clay + Silt fraction of marshy soils as high as $91 \%$ in some localities while the highest gross clay fraction (up to $55 \%$ ) also can be obtained here. Although the gross clay fraction of Al_D soils is lower than My_W and Al_D soils also represent high average PL, LL, and PI after the My_W soils. The Al_D soils also show high average PL, LL, and PI (Fig. 4d) which could be due to highly plastic clay types. It may be possible because the whole drainage basin of Koill Aru river (see Supplementary document 1 ) is concentrated in the dry zone of the country. Therefore, the occurrence of high plastic clay type in the soils such as illite has more probability. At the same time, the Mannar area in the northwest of Sri Lanka is the most recognized for occurring highly plastic montmorillonite type clay (e.g. Senevirathna and Senaratne, 2011).

Re_W are shown with a wide range of $\mathrm{PL}, \mathrm{LI}$, and $\mathrm{PI}$, possibly due to Atterberge limits directly correlated with parent rock from which soils were derived. Higher PI values can be obtained from soils over the Garnet Biotite Gneiss while those soils were mainly classified as SC while the lowest PI over the Hornblende Biotite Gneiss which represent soil groups mainly SM and SM-SC. Soils derived over Marble and Undifferentiated Charnockite exhibit intermediate PI values. Soil which has been developed over Hornblende biotite gneiss has relatively high PL although gross clay and gross silt fraction are relatively less. Seed et al. (1964), pointed out, at a range of the small amount of clay fraction, the PL is independent of clay content or increases slightly with simultaneous increases of non-clay content due to the frictional 
resistance between non-clay particles. Soils with plastic soils in SED_D, Al_W and are represented by lower Atterberg limits because those soil are associated with a lower fine-grain faction. PL and LL are closely associated with SED_D, and as a result, the lowest PI can be obtained.

\subsubsection{Plasticity of Soils}

The position of soil as defined on Casagrande's (1948) plasticity chart is a useful indicator of its engineering properties. Soils that plot well below the " $A$ "- line has good engineering properties (Wesley, 2010). The soil in general has higher plasticity under cold and dry weather conditions and lower plasticity under warm and wet weather conditions (Scott and Yates1931).

Soils collected from various depths in Re_W have represented an uneven distribution with low to high plasticity (Fig. 5a). Plasticity has no significant relationship with the depth except for soils in the My_W (Fig. $5 b$ ), where the LL and PI of marshy soils show a linear relationship. The data were plotted around the " $A$ " line while LL and PI were decreased with depth. Soils studied from the marshy area lie along with the abandoned paddy fields and it extended more than $20 \mathrm{~km}$ along a structural lineament (Supplementary Fig. 3). During the rainy season, the Kaduwala area is frequently subjected to flood since the overflow of the Kalani river (Basnayake et al. 2007). Therefore, stratification of sediments deposited in the soil profiles can be observed.

Alluvial soils collected from 1.00 to $15.00 \mathrm{~m}$ in the wet zone are generally plotted into the shaded area (named CL-ML) of the plasticity chart (Fig. 5c). Low clay fraction could be mainly responsible for the low plastic behaviour of those soils. Soils in the upper $16 \mathrm{~m}$ of Al_D soils (Fig. $5 \mathrm{~d}$ ), indicated low to intermediate LL $(27 \%-47 \%)$ and relatively high PI ( $8 \%$ - 16\%) compared to Al_W soils.

All the soil samples from Co_D (Fig. 5e) were plotted above the "A" line and had low plasticity, especially those SPT boreholes around Batticaloa located within the sandbars toward the seaward from the Batticaloa lagoon. These sand bars may represent former barrier islands with specific depositional characteristics due to genetic history. As a result, within the upper $3 \mathrm{~m}$, all soil types were classified as SW and SP. However, considering the locations around Pottuvil, non-plastic soil groups (SW and SP) are prominent while SC group occurs in SPT holes closer to small tanks (Villu).

Since the shell of the earth-dams is generally constructed using clay-poor, and sand-rich well-graded soils, SED_D (Fig. 5f) is characteristics with low PI (generally $>7$ ) and relatively low LL (mostly >25).

\subsubsection{Natural Moisture Content (NMC)}

When classifying cohesive soils and assessing their engineering properties, moisture content (or water content) measurements, both in the natural state and under defined test conditions, could offer us extremely useful information. Figure 6 a shows the variation of natural moisture content of studied soils (except for Co_D). Marshy soils represent the highest NMC out of all soils studied since they contain clayrich soil groups mostly confined to water-saturated conditions. However, soils in the earth dams located in the dry zone usually consist of well-compacted soils. Since the void spaces are minimal resulting in the 
lowest moisture content of those soils. Vanapalli (1996) pointed out that the electrostatic force within the soils is increasing with decreasing water content which leads to the soil particles being packed closer. Hence the soil itself becomes more compact and strong.

\subsubsection{Liquidity Index (LI)}

The liquidity index (LI) provides a quantitative measure of the current state of soils. The softness of saturated clay can be expressed numerically by the liquidity index. Values of LI greater $\geq 1$ are indicative of liquefaction or "quick" potential. In other words, the soil structure may be converted into a viscous fluid when disturbed or remolded by pile driving, caisson drilling, or helical screw foundation installation.

The highest LI is represented by My_W where most of the soil behaves plastic to the liquid state (Fig. 6b). However, Re_W and Al_W soils behave differently from above with plastic to semisolid.-state. The SED_D and AI-W are represented mostly by negative LI values, indicating semi-solid or solid behaviour (Fig. 6b). Since the moisture content lacks in the data set from the soils in the coastal-dry zone, LI was not calculated.

\subsubsection{Compression Index (Cc)}

The consolidation settlement of a structure founded on a normally consolidated soil can be calculated from the knowledge of the compression index (Robinson and Allam 2003). It has been postulated that the determination of Cc has many practical significances, especially during the planning stage of a construction project, since it permits computations of approximate settlements of structures founded on particular soils.

Since the well-controlled primary compaction in SED_D is high, it represents the lowest compression index. As it leads to less porosity due to artificial compaction, those soils would contain lower moisture content and result in decreased Cc. When the moisture content is incasing, simultaneously the compressibility of the soil is also increased up to optimum moisture content. Re_W represents a wide range of $\mathrm{Cc}$ (Fig. $6 \mathrm{c}$ ) which could be due to those soils derived from various rock types. For example, soils derived from hornblende-biotite gneiss, $\mathrm{Cc}$ range from 0.043 to 0.162 . However, soil derived from undifferentiated charnockitic gneiss and garnet-biotite gneiss, Cc ranges from 0.124 to 0.270 and from 0.170 to 0.536 respectively. For soils derived from marble Cc range from 0.043 to 0.484 (Fig. 6c).

The highest $\mathrm{Cc}$ values of plastic soils can be encounter in $\mathrm{My}$ _W where $\mathrm{OH}$ associates the highest (0.36) while SC has the lowest (0.07). Usually, highly organic soils are characterized by a high compression index (Ying and Michael, 2011). Therefore, in most instances, organic soil groups such as OH, OL, and $\mathrm{Pt} / \mathrm{CL}$ have represented relatively high Cc values. Peat and organic soils are the toughest foundation soils to be worked with, that exhibit unusual compression behaviour having high compressibility with a significant secondary compression stage (Cola and Cartellazo, 1999). However, MH-like inorganic soils also tend to have high $\mathrm{Cc}$ values as they have high $\mathrm{LL}$ in such weathering environments. 
Al_W also shows a relatively low compression index after SED-W due to low moisture content. Dealing with the plastic soil of Al_D, Cc values are relatively high than Al_W due to high $\mathrm{LL}$ and relatively high moisture content (see Fig. 6a). Plastic soil types of Co_D also show low $\mathrm{Cc}$ and could be placed after the SED_D and AI_W. Since data of only five plastic soil samples were analyzed, the reliability of results in the coastal-dry zone may reduce (all other data were obtained relevant to the non-plastic soils in this environment).

\subsubsection{Activity of Soils}

According to the activity and relative classification of soils (Seed and Lundgren, 1964), all studied soils other than some soils in Re_W and SED_D show inactive clay types (activity $<0.75$ ). The highest range of activity values can be obtained in Re_W (Fig. 6d). The soils derived from garnet-biotite gneiss represent higher activity but those from the hornblende biotite gneiss show lower values. Soils formed over marble exhibit a wide range of activities that vary from $0.12-1.34$. As a result, soil can be classified as inactive to normal clay in Re_W. At the same time, the soil in SED_D can also be classified as inactive to normal clay. In a recent study, Dias and Seneviratne, (2010) show cracking intensity of earth dams is significantly correlated with clay percentage and $\mathrm{Pl}$, so that the activity plays a major role.

\subsubsection{Swell Potential of soils}

The swelling potential is influenced by many factors. Some of which are indigenous to the clay body. The others that are related to its weathering environment and other physical conditions, which include clay mineral composition, amount of non-clay material, density, void ratio, size, the orientation of clay particles, cementation, macrostructure, size, and thickness of the clay body, and depth below the ground surface (Olive et al., 1989). The swelling of soils is often characterized by a high liquid limit and plasticity index with a variable content of more active swelling clay minerals (Youssef et al., 1957; Popesco, 1980, Adhikar et al. 2006). Figure 7 shows a variation of the swell potential of studied soils.

In the top $6 \mathrm{~m}$ Re_W (Fig. 7a), a large number of samples were plotted on low potential expansiveness zone other than the $\mathrm{CL}$ and $\mathrm{SC}$, which are shown under medium swell potential (medium expansiveness). Out of $80 \%$ of SC samples with medium Swell potential in Re_W have been derived from garnet-biotite gneiss. Soils developed over marble and hornblende-biotite gneiss are frequently represented by low swell potential. At the same time, CL derived from undifferentiated charnockitic gneiss also shows medium swell potential. Therefore, in Re_W, the swell potential of soil groups is directly correlated with the lithology.

Upper 5m of My_W exhibits medium to high swell potential. $\mathrm{CH}$ always showed high swell potential while $\mathrm{OL}, \mathrm{OH}$, and SM also showed high swell potential at some locations (Fig. 7c). Jones and Holtz, (1973) showed the volume changes in clay, because of variations in moisture content, occur within about $30 \mathrm{ft}$ of the ground surface. However, most changes that cause engineering problems take place at depths of less than $10 \mathrm{ft}$ (Hamilton, 1963; Gromko, 1974). My-W is mostly saturated throughout the year since water logging capability and availability of water; the shrink-swell behaviour is very limited. Boreholes in marshy (144 boreholes) indicated that the unsaturation zone only encountered from surface level to 1.50 
depths in very few locations. Therefore, it will be very important to pay more attention to the swell potential of the upper $1.50 \mathrm{~m}$ of $\mathrm{My}-\mathrm{W}$ where could force geotechnical problems within this depth zone.

Al_W (Fig. 7b), Co_D (Fig. 7e), and soils in SED_D (Fig. 4f) indicate low swell potential could be a result of the relatively low clay fraction. The presence of silt, sand and other non-clay materials reduce the swelling potential in proportion to their amount. The non-clay materials are dilutants that in effect reduce the claymineral content per unit volume and hence reduce swelling potential (Komornik and David, 1969).

CL with medium expansiveness distributes within the first $6.00 \mathrm{~m}$ depth in Al_D soils (Fig. 7d). Olive et al. (1989) show, maximum volume change for a clay body is directly proportional to the size of the body. However, even thick clay bodies composed of highly expandable clay minerals will have no swelling potential if the weight of the overburden is sufficient to counter swelling pressures. Therefore, SC and SM with which encountered within $8.50 \mathrm{~m}$ it could not behave as expansive soil although those soils were classified as medium expansiveness according to Van Der Merwe's method.

Expansive soil can be identified by several methods. According to the Unified Soil Classification System (USCS) the studied soil is classified as an inorganic fat clay $(\mathrm{CH})$ and/or elastic silt (MH), organic clay (OH) (Fig. 2) with high plasticity, which is an indication of its expansive nature, since most expansive soils are often clayey (Lew, 2010). In Figure 7 some of the experimental data of My_W and Re_D are found to be around the "A-line" and right of the vertical line crossing LL=50\% which is an indication of expansive soils.

\subsection{Empirical Formula Derived for Calculating Plasticity Index of Marshy Soils}

Out of studied soils, plastic soils of marshy soils in the wet zone represented a better linear relationship between liquid limit and plasticity index. Therefore, the linear regression method was provided to base the development of an empirical formula to calculate the plasticity index of soils in tropical marshy soils (Fig. 8). As a result, no need of measuring plastic limit determination to plasticity index. At the same time, as the liquid limit is known and derived equation could calculate plasticity index, plastic limit also could be obtained using general formula. The derived formula is,

$P 1 \%=-1.91+(0.46 * L L \%)$

Where,

$\mathrm{PI}$ - Plasticity index

LL - Liquid limit

Therefore, PL can be determined by the traditional equation,

$P I \%=L L \%-P L \%$ 
At present most of the geotechnical laboratories throughout the world are determined the plastic limit of soils according to ASTM Standards. It specifies the value of plastic limit as the moisture content of rolled soil thread at $3.2 \mathrm{~mm}$ diameter begins to crumble. The reliability of test results must depend on the skill of the operator and various mechanical factors. In practice, test results of plastic limit have a high variation. Therefore, obtained PI by on empirical formula and based on it finding PL is very easier and saves time during soil investigations. Therefore, the formula obtained by liner recreation analysis is helpful to future geotechnical investigations in marshy. The reason for such a strong linear relationship between LL Vs PI may be a higher fine-grain fraction of My_W.

\subsection{Standard Penetration Test (SPT) Data and Strength properties of soils}

The Standard Penetration Test (SPT) is a common "in-situ" testing method used to determine the geotechnical engineering properties of subsurface soils and is currently the most popular and economical means to obtain subsurface information. SPT-N values of deferent soil profiles were analyzed in three depth zones, $0.00-6.00 \mathrm{~m}, 6.00-12.00 \mathrm{~m}$, and 12.00-16.00m (Supplementary Fig. 6a to f). The Unconfined Compression test is used to measure the shearing resistance of cohesive soils (Oyediran and Durojaiye, 2011). Friction angle $\left(\varnothing^{0}\right)$, relative density $(\%)$, and competency were calculated using methods after Meyehof (1956) while consistency and approximate Unconfined Compressive strength were determined according to the method after Arvind and Dhananjaya, (2003). SPT-N value ranges and predicted competency, consistency, and approximate unconfined compressive strength, friction angle, and relative density of Re_W, Al_W, My_W, AI_D, Co_D, and SED_D respectively are given (Figs. 9a to $9 \mathrm{f}$ and Supplementary Tables 1 to 6 ). The highest SPT-N values of $0.00-6.00 \mathrm{~m}$ were obtained within the SED_D soils which may be due to artificially induced well-compacted nature. Since natural moisture content is also very low, these soils generally fall into hard consistency. Therefore, higher SPT values can be associated with soil groups such as SC (34-44), SM (30-36), GM (>50), and GW (>50) (Supplementary Fig. 6f). Competency, consistency, and approximate unconfined compressive strength, friction angle, and relative density of SED_D soils are higher than all other soils (Supplementary Table 1). Sandy soils with plastic properties show the widest SPT-N ranges in Re_W when compared with the others.

In addition, AI_D also represents a high average SPT-N value within the fine-grain soil groups, although those soils contained relatively high moisture content (Supplementary Fig. 6d). Since river Koill Aru flows on quaternary limestone terrain, it is possible to dissolve and precipitate a significant amount of calcium carbonate. It could cause some form of cementation within the subsoil which resulted in high SPT. The highest SPT $-\mathrm{N}$ values for ML (28-48) were recorded out of all studied soils in Al_D soils within this depth zone. However, fine soil groups such as $\mathrm{CH}$ (5), CL (8), and ML (17-21) (Supplementary Fig. 6a) in Re_W show low SPT-N values. Moreover, sandy soil groups such as SP (>50), SW (>50), and SM-SC (36) in Re_W show high average SPT-N values, which may be due to the residual soils been developed by "insitu" weathering. Therefore, those soils are generally compacted than other naturally transported soils. Re_W soils derived from the hornblende biotite gneiss show relatively high SPT-N values (from 14->50) 
compared to the soils derived from garnet-biotite gneiss (from 11->50), undifferentiated charnockitic gneiss (from 3->50), and marble (from 3-47) in that order.

The lowest SPT-N values were observed within the top $5 \mathrm{~m}$ in My_W soils, where SPT-N values vary from 1 - 44 (e.g. CL (1-18), CH (2-3), OH (1-17), Pt/CL (1-4)). The highest SPT-N values were observed in SW (331) and SP (1-35) (Fig. 9c). The "N" values are ranging from 1 to 28 in fine-grain soil groups. Soils encountered in marshy areas contain higher fine-grain fractions and high moisture content. Therefore, most of the soils are behaved as plastic to liquefied state according to LI values (Fig. 6b). The lowest competency and consistency of all soil groups varies from very loose to medium dense and from very soft to very stiff or hard respectively while lower approximate unconfined compressive strength, friction angle, and relative density are associated within My_W (Supplementary Table 2).

Plastic soils encountered within the upper $6.00 \mathrm{~m}$ of Al_W are represented by low SPT-N values (eg. CL-ML (2), ML (2-5), and SM (6-12)) and compared with the Al_D soils having SPT- $N$ value ranges $(M L=2, S M=6$, SM-SC=18) of (Supplementary Fig. 6b). At the same time are SPT ranges also narrow. It may be due to the poorly cemented or loose nature of these soils.

The upper $3.00 \mathrm{~m}$ of Co_D, SPT-N values were ranging from 4 to 34 . SW represents the highest " $\mathrm{N}$ " values $(\mathrm{N}=34)$ while SC with lowest " $\mathrm{N}$ " value $(\mathrm{N}=4)$ within the SW (Supplementary Fig. 6e). The interesting observation is although the coastal soils represent very low " $\mathrm{N}$ " values, the " $\mathrm{N}$ " values of SP and SW within the top few meters are very high compared to other soils. Based on resulted " $\mathrm{N}$ " values, competence and consistency of fine-grain soil vary from loose to hard and from firm to hard respectively. Since coastal soils have been derived by wave action those soils are uncemented and poorly compacted. Therefore, often low SPT-N values are associated with those soils. However, the SC soil group shows high SPT values with the mean strength of the coastal soils are increased when fine fraction soil percent is increased. It is a characteristic feature for Co_D as well, where sand grains are bonded and cemented together by a clay matrix.

SPT-N values within $6.00 \mathrm{~m}-12.00$ and $12.00 \mathrm{~m}-16.00 \mathrm{~m}$ were obtained only for Al_W, Al_D, and SED_D soils. Although low SPT-N values were obtained within the top $6 \mathrm{~m}$ in Al_W, it was changed from 14 to 33 at $6.00 m-12.00$ depth zone and further increased from 29 to $>50$ at $12.00 m-15.00 m$ depth zone. The " $\mathrm{N}$ " values of sandy soil groups such as SM, SM-SC, and SP are varied within a wider range in Al_W soils compared to other soils.

Soils in Al_D, SPT-N values were ranged from 18 to $>50$ at depth zone $6.00 \mathrm{~m}-12.00$ while values were increased from 33 to $>50$ at $12.00 m-15.00 m$ depth zone. It could be a result of high cementation by $\mathrm{CaCO}_{3}$ and well compaction when going deeper. As shown in Figure. $5.15 \mathrm{~d}$, the highest " $\mathrm{N}$ " value at $6.00 \mathrm{~m}-12.00 \mathrm{~m}$ depth zone was obtained within SW (42-50). Depth zone $12.00 \mathrm{~m}-16.00 \mathrm{~m}$ highest " $\mathrm{N}$ " value $(\mathrm{N}>50)$ recorded within $\mathrm{SW}, \mathrm{SM}$, and $\mathrm{CL}$ while lowest (44->50) observed within SP. It was clearly observed that the average " $\mathrm{N}$ " value of the same soil group increased with increasing depth in AL_D soils as observed as Al_W. 
Ranges of SPT-N values in SED_D soils at 6.00-12.00m and 12.00-16.00m are concentrated toward the highest order SPT values of the graph (Supplementary Fig. 6f). SW-SC showed a relatively high "N" value in all three depth zone. However, SM show relatively low average "N" values in the $6.00 \mathrm{~m}-12.00 \mathrm{~m}$ depth zone than the upper $6.00 \mathrm{~m}$. It could be due to the presence of a groundwater table at this depth zone. Therefore, soils can become wet and swell which could result in a relative density of 65-80 range.

\subsection{Overview of the study}

Field geotechnical research needs data from various sources and therefore, it is a challengeable and tough task that needs significant input from consulting firms, government departments, and individual technical personnel. One of the key problems faced by the researcher is how to collect very expensive and sometimes classified geotechnical data. It is a common consensus that extracting geotechnical data from numerous construction projects in many parts of the world is difficult and needs to overcome legal and ethical issues and constraints. Moreover, the major concern however is the consistency of available data since various geotechnical investigations are focusing on different objects. For instance, geotechnical investigation of road construction (e.g. Song et al., 2003) may differ from the investigations carried out on the bridge and multi-story building sites (e.g. Handa et al., 1984). In road construction, much attention pays to the upper part of the soil sections, whereas for bridge construction, depth to bedrock or lower stratum of the soil sections is excessively investigated. On the other hand, hydrogeological and mining activities are rendered with different datasets which will be generated through different techniques. Therefore, it is much more a tough task to focus on existing geotechnical data collection from different construction projects. The present study however endeavors to overcome some of these problems and to achieve a satisfactory result from existing geotechnical data.

At the same time, statistical analysis of soil properties encountered many difficulties; the first of them being the poor quality of geotechnical tests and their results (Moussouteguy et al. 2002). It is therefore important to properly categorized, catalogued, and assess the data in order to maintain the quality. Thus, it will be possible to validate any statistical output results by testing various limitations including stability, fussiness, and awkwardness associated with when sampling more or less "reliable" data set. However, geotechnical prospecting will remain indispensable. A better knowledge of the subsurface provides a better guide; for instance, with a more reliable estimate of requested depth to reach the sufficiently bearable substratum, or layers of good characteristics (Breysse et al., 2006).

Several important factors were observed in this study. One is a soil classification mechanism applicable to borehole logging. During borehole logging, soils are immediately classified in the field, based on general observations and individual loggers' experience and senses of soils. Such human intervention and time constraints may lead to confusion. We observed soils with approximately the same plasticity and grain size distributions been classified under different names in the log sheets. On the contrary, sometimes, soils with completely different plasticity and grain size distribution may be classified under the same name. Such output leads people who refer to these log sheets to get ambiguous information on soils which will have real difficulty when interpreting. Therefore, soil groups in the log sheets should be assigned according to a reference standard after completion of the laboratory tests such as sieve 
analysis and soil consistency limits. Then any professional engineer or geologist who lives in any part of the world could infer soil properties confidently with more clarity as soils have been classified with a standard method.

Other is the distribution of geotechnical properties in residual soils. Most of the geotechnical engineers and engineering geologists presume residual soils usually cause fewer geotechnical problems compared to the transported soils. However, since geotechnical properties are directly correlated with the parent material on which the soils were formed, and weathering phenomena based on topography causing different results. If the terrain is consists of complex geology with the distribution of different rock types, the respective geotechnical properties may also vary. Therefore, proper investigation of soil properties is an essential prerequisite even within the residual soils before any construction work is commissioned.

The third one is a factor based on the genetic distribution of soils under different climatic regimes. The soils in the wet zone have a large number of soil groups compared to the dry zone leads to a wide variation of plasticity and gradation. Therefore, during soil investigation, due concerns should be given to the soils developed in the wet zone compared to the dry zone.

\section{Conclusions}

- Geotechnical properties of soils depend on specific exogenous processes and climatic conditions prevailed in their genetic environment.

- Soil plasticity and grain size distributions in soils are varied within a wide range in the wet zone. Therefore, soil can be classified into several groups, such as .....

- Geotechnical properties of residual soils in the wet zone show a strong relationship with the source rock. Since several rock types are present, it shows a broad range of variation in geotechnical properties.

- Since the occurrences of both high and medium swell potential and readily fluctuating unsaturated zone in the soil, more attention should be extended to the upper $1.50 \mathrm{~m}$ within the marshy-wet zone during shallow construction.

- alluvial soils in the dry zone show relatively high strength properties in contrast with the wet zone.

- $\mathrm{LL}$ and PI of marshy soils in the wet zone are strongly correlated $\left(\mathrm{R}^{2}=0.83\right)$ and it could be due to high clay fraction. Based on the results an empirical formula PI\% $=-1.91+(0.46$ * LL \%) could be obtained for such soils.

- Soil groups in SPT log sheets must be assigned according to a standard practice probably supported by subsequent proper laboratory testing instead of directly classifying them in the field based on general observations and personnel assessments.

\section{Declarations}

\section{Acknowledgements}


We express our sincere thanks to Mr. Nishantha Hikkaduwa, Managing Director/Engineering Geologist of the GeoEngineering Consultant (Pvt) Ltd, for kindly providing us with all the necessary borehole data, other relevant geological information, and laboratory facilities. Our special thanks go to Soil Tech (Pvt) Ltd, Rajagiriya, for kindly providing us with the borehole data from Polonnaruwa. The first author wishes to express his thanks to Mr. S. Sanjaya, Mr. N. Chamara (Geologist), Mr. C. Gamage (Director/Engineer Soil Tech Ltd), and Mr. D.N. Wijerathna (Engineering Assistant) of Geo-Engineering Consultant (Pvt) Ltd, for kindly extended their field experiences relevant to soil investigation projects.

\section{References}

1. Amadi, A.N., Akande W. G., Okunlola I.A., Jimoh M.O. \& Deborah, F.G. 2015. Assessment of the Geotechnical Properties of Lateritic Soils in Minna, North Central Nigeria for Road design and Construction. Am. J. Min. Metall, 3, 15-20.

2. Archer, J.R. 1975. Soil consistency. In: Soil Physical Conditions and Crop Production. Ministry of Agriculture, Fisheries and Food, Tech. Bull. 29. London: HMSO. pp 289-297.

3. Aruvind, V.S., Dhananjay L.S. 2003. Soil Mechanics and Geotechnical Engineering, A.A Balkema, a member of Swets and Zeitlinger Publishers, India, ISBN 905809235 6, pp 372

4. Akinmusuru. J.O., Adebayo. J.O., 1981. Fiber reinforced earth block,\|l Proceedings of the Am. Soc. Civil Eng., 107, 487- 496.

5. Arthur, W.W., 1949. Atterberg plastic limits of clay minerals. Am. Mineral. 34, 508-512.

6. Blair, S.G.W., Yates, F., 1931. The effect of climatic variations on the plasticity of soil. J. agric. sci. 22, 639-646.

7. Breysse, D, Piette, C, Marache, A., Fabre, R., 2006. Data analysis and geotechnical properties modelling of urban soils: the case of Pessac, Gironde. The Geo. soc. London.IAEG2006 paper number 73.

8. Campbell, D.J., 2001. Liquid and plastic limits. In: Smith, K.A., Mullins, C.E., (Eds.), Soil and Environmental Analysis, Physical Methods. Dekker Inc. New York. pp 349-375.

9. Casagrande, A., 1932. Research on the Atterberg's limit of soils. Public Road 13, 121-130.

10. Chance Company, A.B., 2003, Helical screw foundation system design manual for new construction, Hubbell, Inc. http://www.vickars.com/screwpile_manual/

11. Chenari, R.J., Tizpa, P., Rad, M.R.G., Machado, S.L., Fard M.K., 2015. The use of index parameters to predict soil geotechnical properties. Arab. J. Geosci. 8, 4907-4919.

12. Cooray, P.G., 1984. An introduction to the Geology of Sri Lanka. $2^{\text {nd }}$ revised edition, Ceylon National Museum Publication, Colombo, 81-116 pp.

13. Cooray, P.G., 1994. The Precambrian of Sri Lanka: a historic review. Precambrian Res. 66, 3 - 18. 
14. Daniel, D.E., Benson, C.H., 1990. Water content-density criteria for compacted soil liners. J. Geotech. Eng. 116, 1811-1830.

15. Didei, I. S., Oki, A.O., Akana, T.S., 2016. Exploring the geotechnical properties of soil in Amassoma, Bayelsa State, Nigeria for classification purpose using the unified soil classification systems. International Journal of Latest Research in Engineering and Technology (IJLRET), 2, 51-55.

16. Germaine, J.T., Amy V.G., 2009.Geotechnical laboratory measurements for engineers, Jone Wiley and Sons, Canada, pp. 118.

17. Gromko, G.J., 1974. Review of expansive soils: American society of civil engineers, J. Geotech. Eng. Div., 100, 667-687.

18. Hamilton, J.J., 1963, Volume changes in undisturbed clay profiles in Western Canada. Can. Geotech. J. 1, 27-42.

19. Handa, S.C., Saran, S., Ramasamy, G., Rao, A.S.R., Prakash, B., 1984.Geotechnical Investigations for Foundation Design for Multistoreyed Building" (May 6, 1984). International Conference on Case Histories in Geotechnical Engineering. Paper 5. http://scholarsmine.mst.edu/icchge/1icchge/1icchge-theme8/5

20. Jefferson. I., Rogers. C.D.F., 1998. Liquid limit and the temperature sensitivity of clays, ,l Eng. Geol. 49, 95-109.

21. Johnson, C.L., 2006, Soil fundamentals,crop production and soil management series.FGV-00242, pp. 1-7.

22. Jones, D.E., Holtz, W.G., 1973. Expansive soils-the hidden disaster. Civil Eng. 43, 49-51.

23. Katupotha, J., 1994. Quaternary Research in Sri Lanka. J. Geol. Soc. Sri Lanka. 5, 141-152.

24. Komornik, A., David, D., 1969, Prediction of swelling pressure of clays: American society of civil engineers. Journal of soil mechanics and foundations division, 95, 209-225.

25. Lee, P.W., 1961. Ceramics. Reinhold Publishing Corporation, New York; Chapman and Hall Ltd. London. 93pp.

26. Madugalla, T.B.N.S., Senanayake, S.M.D.N., Jayasena, H.A.H., 2010. Application of geostatistics for the assessment of bedrock and water table distributions (Abs.), 2010 - Peradeniya University research sessions (PURSE), mathematical and physical sciences II: p 221.

27. Malmgren, B.A., Hullugalla, R., Lindeberg, G., Inoue, Y., Hayashi, Y., Mikami, T., 2007. Oscillatory behaviour of monsoon rainfall over Sri Lanka during the late 19th and 20th

28. McBride, R.A., 2008. Soil consistency and lower plastic limits. In: Carter MR, Gregorich EG (eds.), Soil Sampling and Methods of Analysis, 2nd edition, Chapter n58, CRC Press. 761-769 pp.

29. Mapa, R.B. Somasiri, S., Nagarajah, S., 1999. Soils of the wet zone of Sri Lanka, Soil science society of Sri Lanka. special publication 1.

30. Milisenda, C.C., Liew, T.C., Hoffman, A.W., Köhler, H., 1994. Nd isotopic mapping of the Sri Lanka basement: update and additional constraints from Sr isotopes. Precambrian Res. 66, 95- 110. 
31. Mbagwa, J.S.C., Abeh, O.G., 1998. Prediction of engineering properties of tropical soils using intrinsic pedological parameters. Soil Sci. 163, 93-102.

32. Moussouteguy, N., Breysse, D., Chassagne, P., 2002. Decrease of geotechnical uncertainties via a better knowledge of the soil's heterogeneity: combined use of instantaneous diagraphies and pressuremeter test. Eur. J. Env. Civil Eng. 6, 343-354.

33. Moormakn, F.R., Panabokka, C.R., 1961. Soils of Ceylon, a new approach to the identification and classification of the most important soil groups of Ceylon, government press, Ceylon, pp .12.

34. Keller T., Dexter, A.R., 2012. Plastic limits of agricultural soils as functions of soil texture and organic matter content. Soil Res. 50, 7-17.

35. Kröner, A., Cooray, P.G., Vitanage, P.W., 1991. Lithotectonic subdivision of the Precambrian basement in Sri Lanka. In: Körner, A. (Ed.), The Crystalline Crust of Sri Lanka, Part-1. Summary of Research of the German-Sri Lankan Consortium. Geol. Surv. Dep., Sri Lanka, Professional paper 5, pp. 5- 2.

36. Oke, S.A., Amadi, A.N., 2008.An assessment of the geotechnical properties of the subsoil of parts of federal University of Technology, minna, Gidankwano Campus, for foundation design and construction. J. Sci. Educ. Technol. 1, 87-102.

37. Oyediran, I.A., Durojaiye, H.F., 2011. Variability in the Geotechnical properties of some residual clay soils from southwestern Nigeria. Int. J. Sci. Eng. Res. 2, 235-240.

38. Pathirana, H.D.N.C., 1980. Geology of Sri Lanka in relation to plate tectonics. J. Natl. Sci. Found. Sri Lanka, 8, 75-85.

39. Rawa, A.A., Goosen, M.F.A., 2006, Expansive soil: resent advances in characterization and treatment, A.A. Balkema Publishers, pp. 173.

40. Robinson, R.G., Allam, M.M., 2003, Compression index of clays and silts, J. Test. Eval. 31 (1).

41. Rowe, R.K., 2011. Geotechnical and geoenvironmental engineering handbook, Kiuwer academic publisher, United state of America, pp. 48-50.

42. Savage, P. F., 2001, Rural road betterment consideration when using CBR plus and con-aid materials, $1^{\text {st }}$ Africa T2 conference 2001, pp. 378-390.

43. Senevirathna, S.M.N.M., Senaratne, A., 2011, Characterization and beneficiation of montmorillonite in clay deposits, Murunkan, Sri Lanka proceedings of the Peradeniya University research sessions, Sri Lanka, Vol. 16.

44. Seybold, C.A., Elrashidi, M.A., Engel, R.J., 2008. Linear regression models to estimate soil liquid limit and plasticity index from basic soil properties. Soil Sci. 173, 25-34.

45. Sideri, D., Modis, K., Rozos, D., 2016. Multivariate geostatistical modelling of geotechnical characteristics of the alluvial deposits in West Thessaly, Greece. Bull. Eng. Geol. Environ. 73, 709722.

46. Skempton, A.W., 1944. Notes on the Compressibility of Clays. Quar. J. Geol. Soc. London. 100, 119135. 
47. Skempton, A.W., 1953. The colloidal activity of clays. Proc. 3rd Irrterrza ional conference on soil mecharlics and foundatiort engirreerirrg, 1, 57-61.

48. Song, Y.S., Yun, J.M., Hong, W.P., Kim, T.H., 2003. Investigation of solid waste soil as road construction material. Environ. Geo. 44, 203-209.

49. Tezaghi, K., Pech, R. B., 1967. Soil Mechanics in Engineering practice. John Wiley and Sons Inc., New York, USA. 549pp.

50. Thomas, P.G., 1998, The unified soil classification chart relationship between swell index and Atterberg limits pp. 89-190.

51. Van Der Merwe D.H.. 1964, The prediction of heave from the plasticity index and percent clay fraction of soils, the civil engineer in South Africa 6(6).

52. Vanapalli, S.K, Fredlund, D.G, Pufahl, D.E. dan Clifton, A.W., 1996, Model for the Prediction of Strength with Respect to Soil Suction, Can. Geotech. J. 33, 33-392.

53. Wesley, L.D., 2010, Geotechnical Engineering of Residual soil, Jone Wiley \& Sons Inc, New York, pp 19.

54. Youssef, M.S, Sabry, A.A, Tawfiq M.M., 1957. Substantial consolidation and swelling of clay caused by two intersecting cases of serious damage to hospital building in Egypt. Int. Conf. Soil Mech. Found. Eng. 1: 462-466.

\section{Figures}

\section{Figure 1}

(a) Simplified geology map of Sri Lanka with sampling areas (Modified after Cooray, (1994), (b) Climate map of Sri Lanka with sampling areas 


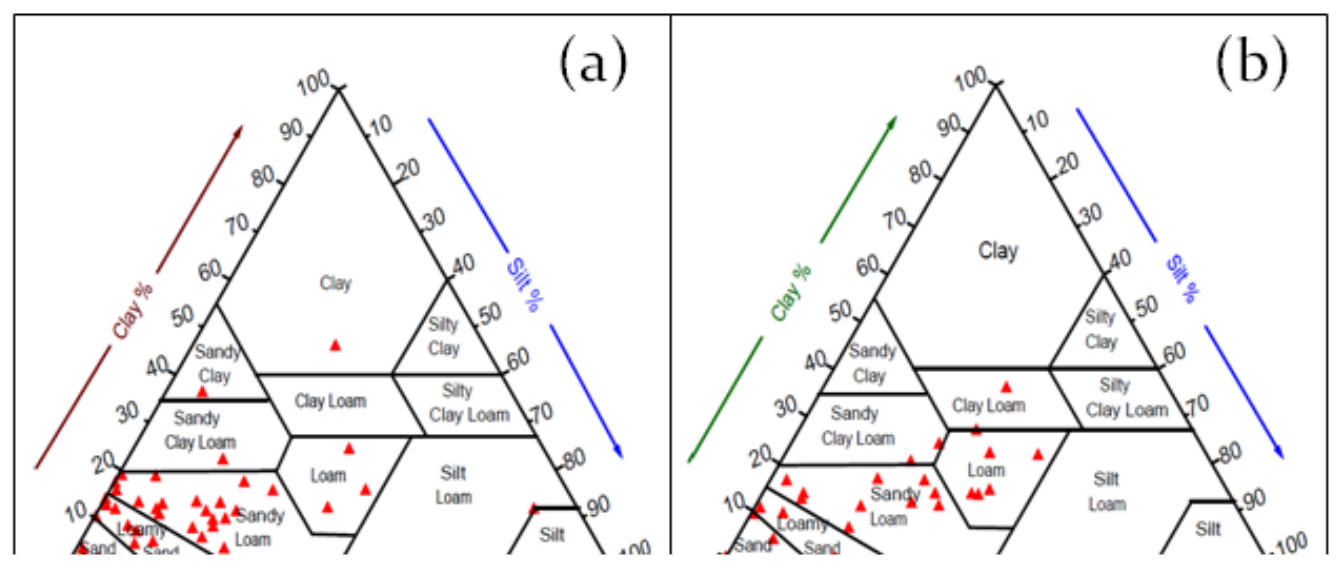

\section{Figure 2}

Textural classification of plastic soils in studied soils. (a) Residual soils- wet zone (Up to $6 \mathrm{~m}$ ), (b) Alluvial soils-wet zone (Up to 15m), (c) Marshy soils- wet zone (Up to $5 \mathrm{~m}$ ), (d) Alluvial soils-dry zone (Up to 16m), (e) Coastal soils-dry zone (Up to $3 \mathrm{~m}$ ), (f) Soil in Earth dams-dry zone (Up to 16m). 


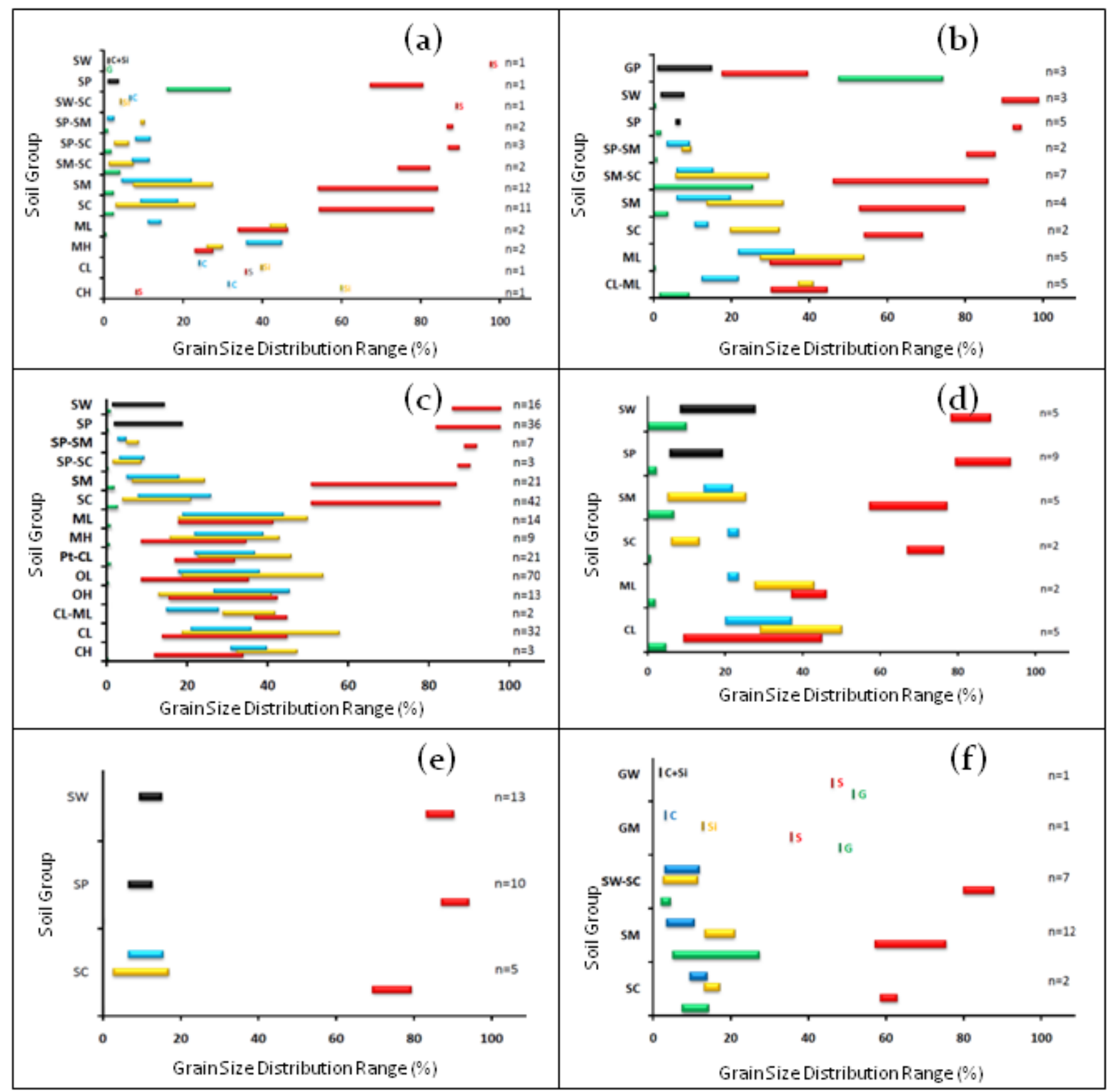

Gravel $\%$ Sand $\%$ Gross Silt $\% \square$ Gross Clay $\% \square($ Clay + Silt $) \%$

* Clay and Silt fraction not separated

Figure 3

Partial size distribution ranges of soils,(a) Residual soils-wet zone (Upper 6m), (c) Alluvial soils- wet zone (Upper 15m), (c) Marshy soils-wet zone (Upper 5m), (d) Alluvial soils-dry zone (Upper 16m), (e) Coastal soils-dry zone (Upper 3m), (f) Soil of Earth dams- dry zone (Upper 16m). 


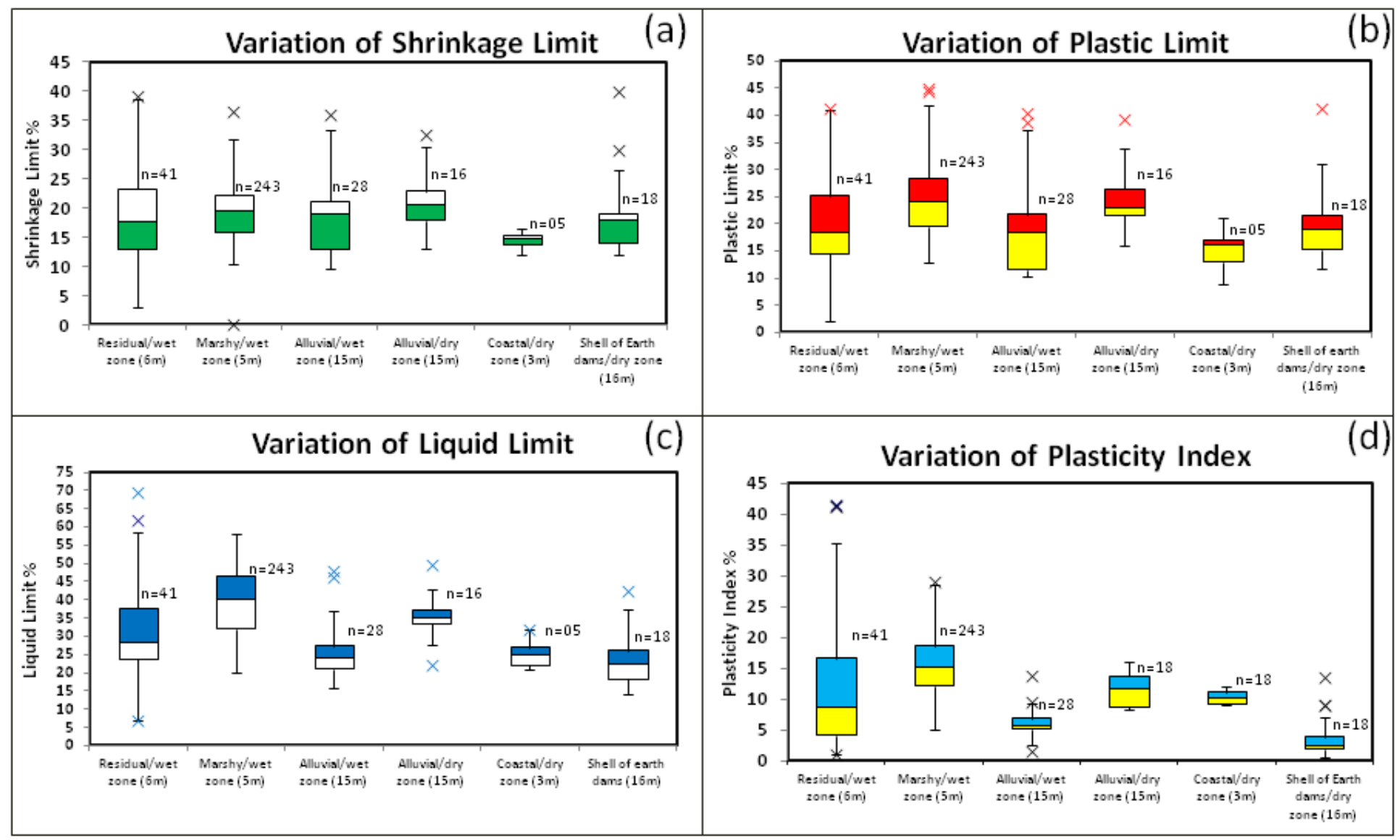

Figure 4

Variation of Soil consistency limits: (a) Variation of shrinkage limit, (b) Variation of plastic limit, (c) Variation of liquid limit, (d) Variation of plasticity index 


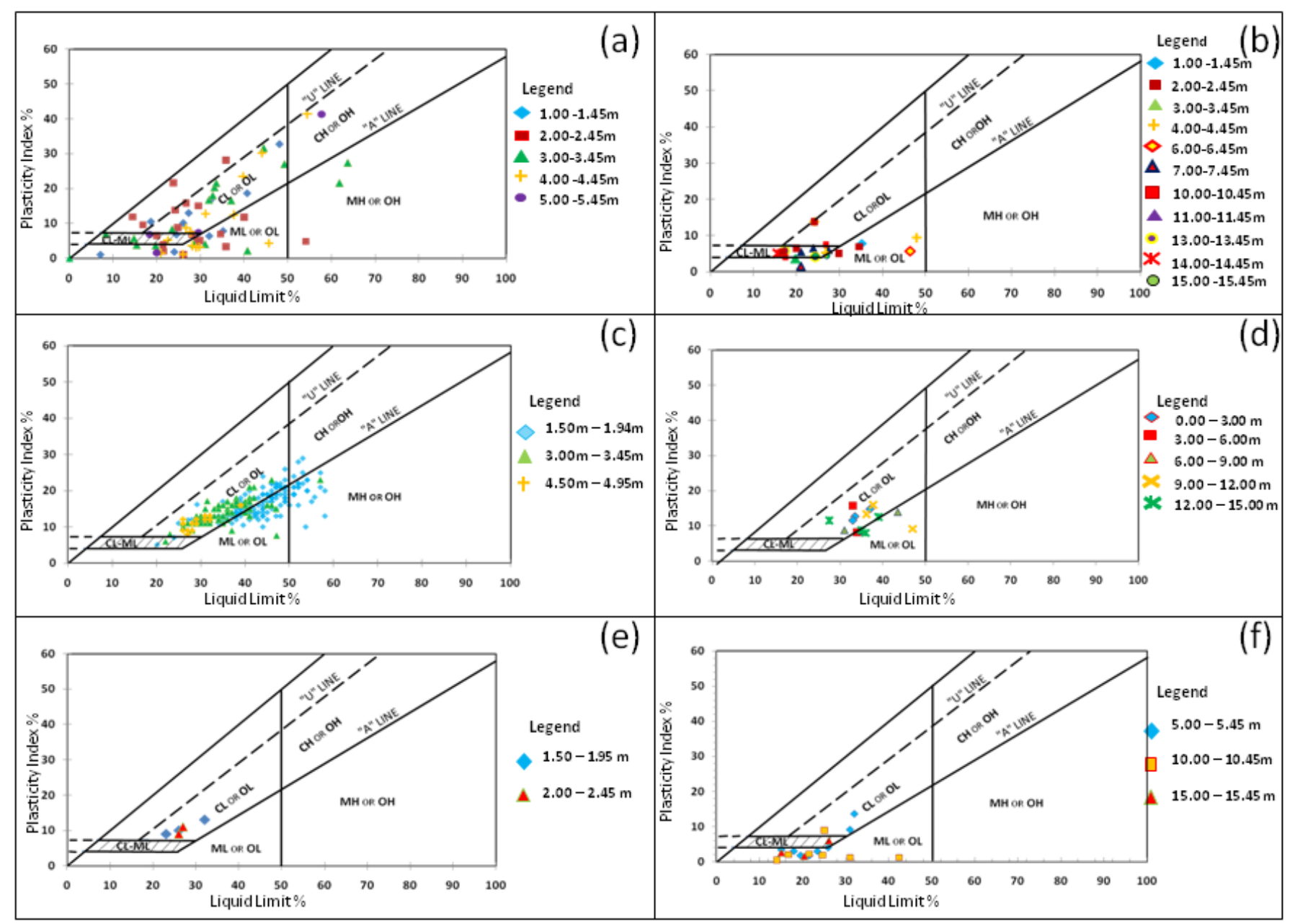

Figure 5

Soils Plasticity of soils on Unified Soil Classification System plasticity chart, (a) Residual soils in the wet zone (Up to6m), Alluvial soils in the wet zone (Up to 15m), (c) Marshy soils in the wet zone (Up to 5m), (c) (d) Alluvial soils in the dry zone (Up to $16 \mathrm{~m}$ ), (e) Coastal soils in the dry zone (Up to $3 \mathrm{~m}$ ), (f) Soil in Earth dams in the dry zone (Up to $16 \mathrm{~m}$ ). 


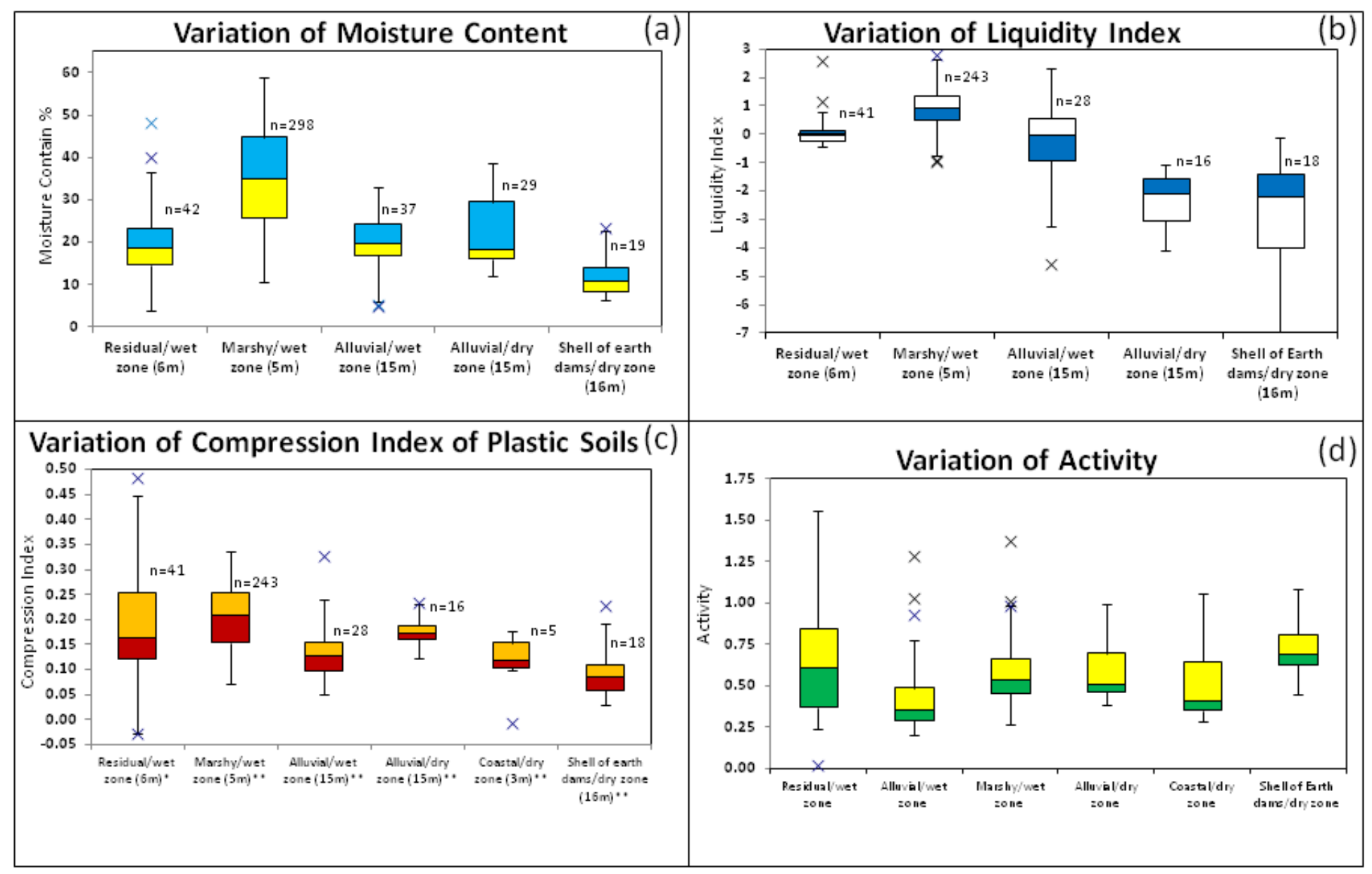

Figure 6

(a), Variation of the natural moisture content of soils, (b) Variation of liquidity index, (c) Variation of compression index in studied soils, (d) Variation of activity of soils 


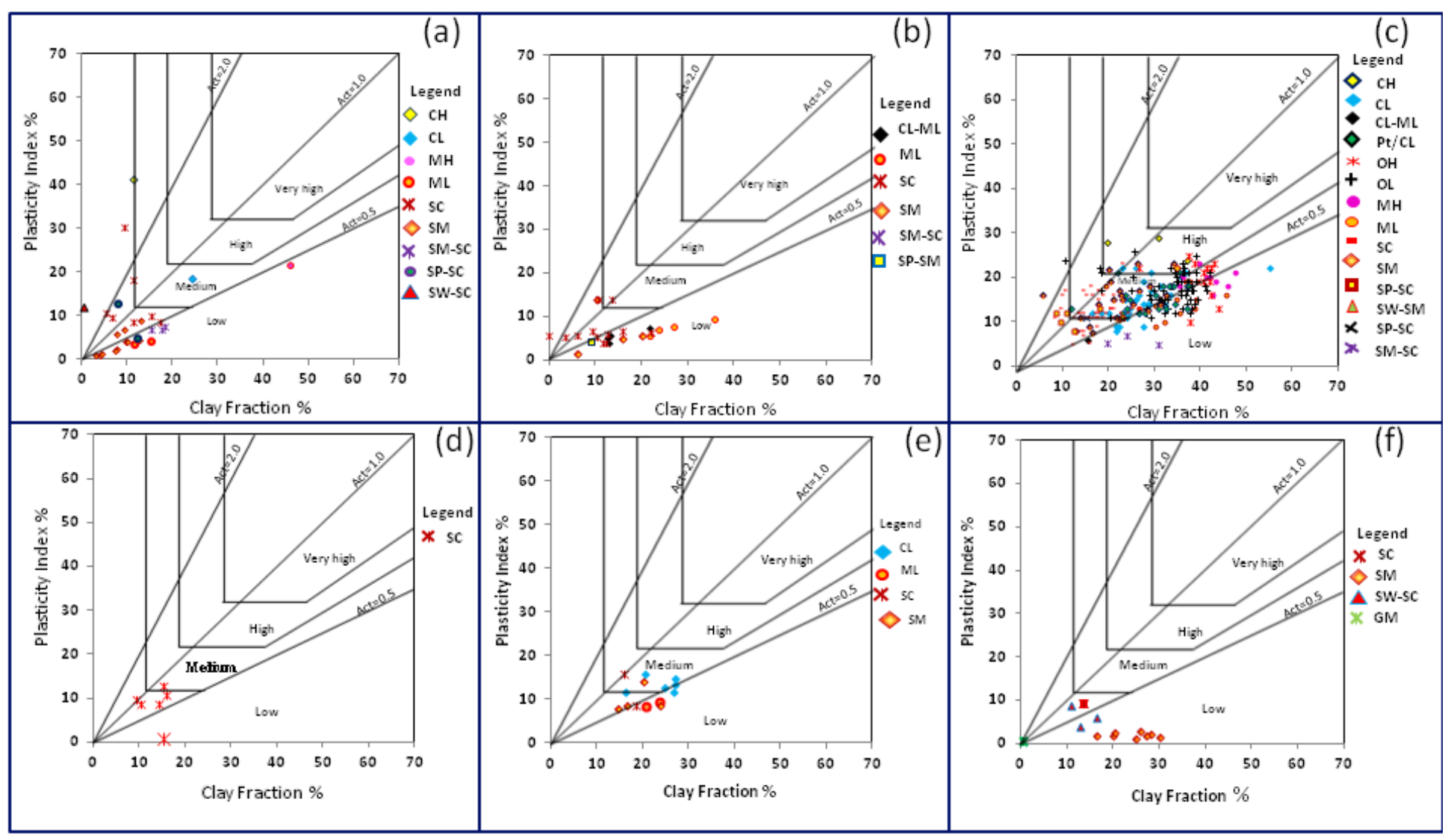

\section{Figure 7}

Swell potential diagrams of Van Der Merwe's (1964) method, (a) Residual soils-wet zone (Up to 6m), (b) Alluvial soils-wet zone (Up to15m), (c) Marshy soils-wet zone (Up to $5 \mathrm{~m}$ ), (d) Alluvial soils-dry zone (Up to $16 \mathrm{~m}$ ) , (e) Coastal soils-dry zone (Up to 3m), (f) Soils in Earth dams-dry zone (Up to 16m).

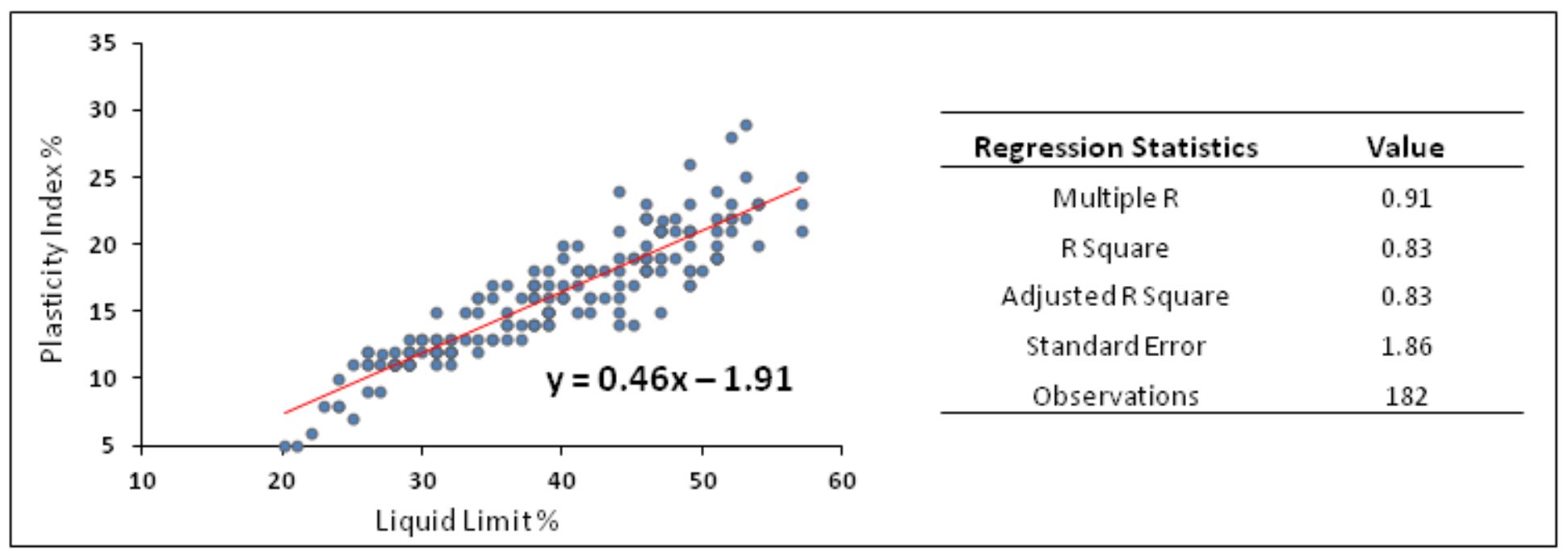

Figure 8

Scatter plot for LL Vs PI of soils in marshy-wet zone 


\section{Supplementary Files}

This is a list of supplementary files associated with this preprint. Click to download.

- SupplementaryDocument1.docx

- SupplementaryFigure1.tif

- SupplementaryFigure2.tif

- SupplementaryFigure3.tif

- SupplementaryFigure4.tif

- SupplementaryFigure5.tif

- SupplementaryFigure6.png

- SupplementaryTable1.docx

- SupplementaryTable2.docx

- SupplementaryTable3.docx

- SupplementaryTable4.docx

- SupplementaryTable5.docx

- SupplementaryTable6.docx 